\title{
Comparison of three radiolabelled peptide analogues for CCK-2 receptor scintigraphy in medullary thyroid carcinoma
}

\author{
Alida C. Fröberg • Marion de Jong • Berthold A. Nock • Wout A. P. Breeman • \\ Jack L. Erion • Theodosia Maina - Marion Verdijsseldonck • Wouter W. de Herder • \\ Aad van der Lugt • Peter P. M. Kooij • Eric P. Krenning
}

Received: 26 November 2008 / Accepted: 12 February 2009/Published online: 6 March 2009

(C) The Author(s) 2009. This article is published with open access at Springerlink.com

\begin{abstract}
Purpose Cholecystokinin 2 (CCK-2) receptor overexpression has been demonstrated in a high percentage of medullary thyroid carcinomas (MTC). Analogous to somatostatin receptors, $\mathrm{CCK}-2$ receptors might be viable targets for radionuclide scintigraphy and/or radionuclide therapy. Several CCK-2 receptor-binding radiopeptides have been developed, and some have been carried through into clinical studies. However, these studies are mostly limited and difficult to compare. The aim of this study was to evaluate the diagnostic and therapeutic potential of three promising CCK-2 receptor-binding radiopeptides in patients with MTC.
\end{abstract}

A. C. Fröberg $(\bowtie) \cdot M$. de Jong $\cdot$ W. A. P. Breeman

M. Verdijsseldonck • P. P. M. Kooij • E. P. Krenning

Department of Nuclear Medicine,

Erasmus MC University Medical Center Rotterdam,

's Gravendijkwal 230,

3015 CE Rotterdam, The Netherlands

e-mail: a.froberg@erasmusmc.nl

B. A. Nock · T. Maina

Molecular Radiopharmacy, I/R-RP, NCSR "Demokritos",

Athens, Greece

J. L. Erion

BioSynthema Inc.,

St. Louis, MO, USA

W. W. de Herder • E. P. Krenning

Department of Internal Medicine, Erasmus MC,

Rotterdam, The Netherlands

A. van der Lugt

Department of Radiology, Erasmus MC,

Rotterdam, The Netherlands
Methods ${ }^{111}$ In-DOTA-(D)Asp-Tyr-Nle-Gly-Trp-Nle-AspPhe- $\mathrm{NH}_{2}$ ( ${ }^{111}$ In-DOTA-CCK), a CCK analogue, and the gastrin-based ligands ${ }^{99 \mathrm{~m}} \mathrm{Tc}^{-N_{4}}$-Gly-(D)Glu-(Glu) $)_{5}$-Ala-TyrGly-Trp-Met-Asp-Phe- $\mathrm{NH}_{2} \quad\left({ }^{99 \mathrm{~m}} \mathrm{Tc}-\right.$ demogastrin 2$)$ and ${ }^{111}$ In-DOTA-(D)Glu-Ala-Tyr-Gly-Trp-Met-Asp-Phe- $\mathrm{NH}_{2}$ ( ${ }^{111}$ In-DOTA-MG11) were each administered to the same group of six patients. Planar images made at 3-5, 7 and $24 \mathrm{~h}$ p.i. were used for comparison of tumour visualisation and renal uptake.

Results ${ }^{99 \mathrm{~m}}$ Tc-demogastrin 2 scintigraphy visualised all known lesions and new lesions in four of six patients. ${ }^{111}$ In-DOTA-CCK and ${ }^{111}$ In-DOTA-MG11 on the other hand missed several lesions; tumour uptake of these two radiopharmaceuticals was quite low. Comparison of retention of renal activity showed no major differences between the three radiopeptides.

Conclusion ${ }^{99 \mathrm{~m}}$ Tc-demogastrin 2 scintigraphy appeared most promising as a diagnostic tool in patients with MTC. Further studies are required to evaluate its value in patient management. Direct comparisons of the compounds studied strongly suggests that ${ }^{111}$ In-DOTA-CCK and ${ }^{111}$ In-DOTA-MG11 have less potential as imaging agents than ${ }^{99 \mathrm{~m}} \mathrm{Tc}-$ demogastrin 2. These DOTA-linked compounds are considered unlikely to be useful for radionuclide therapy because of low tumour uptake.

Keywords CCK-2 receptor · Minigastrin ·

Cholecystokinin $\cdot$ Medullary thyroid carcinoma

\section{Introduction}

Medullary thyroid carcinoma (MTC) originates from malignant de-differentiation of the calcitonin-producing 
parafollicular cells (C cells) in the thyroid. Elevated serum calcitonin is a very sensitive and specific tumour marker for MTC. It can indicate the presence of remaining or recurring tumour after resection of the primary tumour. However, with the available diagnostic imaging modalities [i.e. computed tomography (CT), magnetic resonance imaging (MRI), ultrasound (US), somatostatin receptor scintigraphy (SRS), ${ }^{18}$ F-fluoro-2-deoxyglucose positron emission tomography $\left({ }^{18}\right.$ F-FDG PET)] localisation of the recurrent tumour or metastases (and surgical intervention) often is not possible. In cases of distant metastases there is no wellaccepted treatment available. This makes the development of both a sensitive diagnostic imaging modality and a systemic therapy very important.

The high sensitivity of the commonly used pentagastrin stimulation test suggests a widespread expression of cholecystokinin 2/gastrin receptors (CCK-2 receptors) in MTC and indeed autoradiographic studies demonstrated CCK-2 receptors in $90 \%$ of MTCs (and in a high percentage of several other tumours like small cell lung cancer) [1]. These G protein-coupled receptors bind both CCK and gastrin and might serve as targets for radiolabelled CCK or gastrin analogues for both scintigraphy and peptide receptor radionuclide therapy (PRRT), analogous to the successful use of radiolabelled somatostatin analogues in patients with tumours overexpressing somatostatin receptors $[2,3]$,

Studies in patients with MTC have been performed with both gastrin-like [4-7] and CCK-like peptides [8]. Unfortunately, comparison of the results of these studies is difficult because of the different protocols applied in noncomparable and sometimes small groups of patients.

We decided to investigate and compare three promising CCK-2 receptor-binding peptides in patients with MTC. First: ${ }^{111}$ In-DOTA-(D)Asp-Tyr-Nle-Gly-Trp-Nle-Asp-Phe$\mathrm{NH}_{2}$ ( ${ }^{111}$ In-DOTA-CCK), this analogue showed similar results in animal studies as the ${ }^{111}$ In-DTPA counterpart, which has already been tested in patients [8]. However, the DOTA chelator allows stable radiolabelling with therapeutic nuclides such as ${ }^{90} \mathrm{Y}$ and ${ }^{177} \mathrm{Lu}$ and might enable PRRT. Second: the gastrin-like peptide ${ }^{99 \mathrm{~m}} \mathrm{Tc}-\mathrm{N}_{4}$-Gly-(D) Glu $^{1}$-(Glu) $)_{5}$-Ala-Tyr-Gly-Trp-Met-Asp-Phe-NH ${ }_{2} \quad\left({ }^{99 \mathrm{~m}} \mathrm{Tc}-\right.$ demogastrin 2) that showed very promising results for scintigraphy in animal experiments and also in one patient [7]. Third: ${ }^{111}$ In-DOTA-(D)Glu-Ala-Tyr-Gly-Trp-MetAsp-Phe- $\mathrm{NH}_{2}\left({ }^{111}\right.$ In-DOTA-MG11) is the last peptide that is included in this study. In a patient study by Béhé et al. ${ }^{90}$ Y-DTPA-(D)Glu ${ }^{1}$-(Glu) $)_{5}$-Ala-Tyr-Gly-Trp-Met-Asp-Phe$\mathrm{NH}_{2}\left({ }^{90}\right.$ Y-DTPA-DGlu ${ }^{1}$-minigastrin), tested as a radionuclide therapy candidate, caused serious side effects, including renal insufficiency and bone marrow toxicity [5]. In animal studies, the DOTA-linked des-(Glu $)_{5}$ truncated analogue of minigastrin, ${ }^{111}$ In-DOTA-MG11, showed similar affinity for CCK-2 receptors but significantly reduced renal uptake in comparison with the respective full-length analogue ${ }^{111}$ In-DOTA-DGlu ${ }^{1}$-minigastrin [9]. Due to its low renal retention, this truncated analogue might have therapeutic potential and therefore it was tested in patients showing tumour uptake with one of the other CCK-2 receptor-binding radioanalogues.

The aim of this study was to investigate the biodistribution and compare the diagnostic potential of the three radiolabelled CCK-2 receptor-binding analogues and evaluate the therapeutic potential of the two ${ }^{111}$ In-DOTA compounds in the same patients.

\section{Materials and methods}

\section{Patients}

MTC patients with elevated calcitonin levels after thyroidectomy were sent to the Department of Nuclear Medicine for tumour staging with CCK-2 receptor scintigraphy and/ or to investigate the possibility of PRRT with CCK-2 receptor-binding analogues. Patients underwent scintigraphy with ${ }^{111}$ In-DOTA-CCK and ${ }^{99 \mathrm{~m}} \mathrm{Tc}$-demogastrin 2 . In patients showing tumour uptake, ${ }^{111}$ In-DOTA-MG11 scintigraphy was performed additionally with the aim of localising the maximum possible number of tumour lesions before operation and/or evaluating its potential for radionuclide therapy in patients with distant metastases. Six patients (five women and one man, age: 17-71 years, median: 41 years) were tested with all three mentioned radioligands and included in this study. Calcitonin levels before administration of the first peptide ranged from 0.23 to $131 \mu \mathrm{g} / 1$ (mean: $38.4 \mu \mathrm{g} / \mathrm{l}$ ). Use of ${ }^{111} \mathrm{In}$-DOTA-CCK and ${ }^{99 \mathrm{~m}} \mathrm{Tc}$-demogastrin 2 in patients was approved by the Erasmus MC Medical Review Ethics Committee. ${ }^{111}$ InDOTA-MG11 scintigraphy was performed on a compassionate use basis as allowed by the Erasmus MC Medical Review Ethics Committee. All patients gave written informed consent before each administration. The maximal interval between the three scintigrams was 5 weeks in five patients and 4 months in one patient (patient 1).

Peptide handling, radiolabelling and radiochemical analysis

Radiolabelling of DOTA-MG11 (Radiological Chemistry, University Hospital Basel, Switzerland) and DOTA-CCK (BioSynthema, St. Louis, MO, USA) was performed as described earlier [10]. The procedure was optimised to prevent oxidation and radiolysis. Likewise, the procedure of radiolabelling demogastrin 2 (NCSR "Demokritos", Athens, Greece) [7] was slightly modified to achieve higher specific activity while preventing oxidation and radiolysis 
[11]. Formation and radiochemical purity of the three radiopharmaceuticals were analysed by a combination of instant thin-layer chromatography (ITLC) and highperformance liquid chromatography (HPLC). For all three radiopharmaceuticals an administration of $10 \mu \mathrm{g}$ peptide with the maximal achievable amount of radioactivity was aimed at, resulting in administered doses as described below.

\section{Administration and imaging}

The administered activities were: $216 \pm 19 \mathrm{MBq}{ }^{111} \mathrm{In}$-DOTACCK (11.1 $\pm 0.6 \mu$ g peptide), $773 \pm 97 \mathrm{MBq}{ }^{99 \mathrm{~m}}$ Tc-demogastrin $(9.5 \pm 1.5 \mu \mathrm{g})$ and $186 \pm 34 \mathrm{MBq}{ }^{111}$ In-DOTA-MG11 $(10.8 \pm 1.7 \mu \mathrm{g})$. The radiopharmaceuticals were administered intravenously over a 5 -min period. Blood pressure and heart rate were monitored and patients were asked to report side effects.

Imaging was performed with a dual head camera (Prism 2000XP, Philips, Cleveland, OH, USA) equipped with either a medium-energy $\left({ }^{111} \mathrm{In}\right)$ or a low-energy highresolution ${ }^{99 \mathrm{~m}} \mathrm{Tc}$ ) collimator. Dynamic images of the upper abdomen or known tumour lesions were obtained during $30 \mathrm{~min}$ after injection. Total body images of $10 \mathrm{~min}$ acquisition time were made at $40 \mathrm{~min}$ post (start of) injection (p.i.). Static spot views were obtained at 1, 3-5 and $24 \mathrm{~h}$ p.i. and also at $7 \mathrm{~h}$ p.i. in most cases. Acquisition time of most images was $15 \mathrm{~min}$; only at $24 \mathrm{~h}$ p.i. was the scan time for the ${ }^{99 \mathrm{~m}} \mathrm{Tc}-$ labelled compound $30 \mathrm{~min}$. SPECT images of neck and upper abdomen were made at $4-5 \mathrm{~h}$ p.i. and also at $24 \mathrm{~h}$ p.i. with the ${ }^{111} \mathrm{In}$-labelled radioligands.

Planar images of 3-5, 7 and $24 \mathrm{~h}$ p.i. were used for comparison of the scintigraphy results.

Interpretation of the images

Four nuclear physicians, blinded for the agents used and the locations of the known lesions, evaluated the scans conjointly. Lesions that did not represent normal biodistribution and persisted over time were judged as suspicious for tumour localisation ("positive"). Lesions that were barely visible and/or did not show persisting uptake over time were judged as equivocal. After the random analysis of scans per ligand, also a combination of series of the three ligands was compared with regard to biodistribution and pathological uptake.

Scintigraphic findings were correlated with diagnostic investigations that had been performed earlier. In cases of equivocal or positive lesions in regions without known tumour lesions, correlating imaging was performed. For neck lesions US investigations were performed by an experienced radiologist (AvdL) with knowledge of the location of the lesions on the CCK-2 receptor scintigrams. If corresponding lymph nodes could be localised, fine-needle aspiration cytology was performed (if technically possible). For other unknown lesions $\mathrm{CT}$ and/or MRI were performed which were interpreted by the radiologist with knowledge of the affected organ using standard radiological criteria for malignancy like enhancement patterns, invasiveness, bone destruction and density (CT) or signal intensity (MRI) of lesions. Thereafter, the CT and MR images were correlated with the CCK-2 receptor scintigrams.

Renal uptake was calculated according to the geometric mean method using anterior and posterior planar views and a standard with known activity. Data were corrected for background activity and attenuation (based on CT data). In each patient the same region was used for all calculations (both time points of the three radioligands). If overprojection of activity in other organs hampered the measurement, total counts in the kidney were estimated by multiplying the number of counts/pixel (in the part of the kidney without overprojection) with the number of pixels of the kidney (as defined on early images without overprojection).

\section{Analysis of blood and urine}

Radioactivity in blood samples was measured with a Packard COBRA auto-gamma counting system (Packard, Meriden, CT, USA) and radioactivity in urine samples with a dose calibrator. Blood samples were drawn at 10, 20, 30, 40, 60 and $90 \mathrm{~min}$ and 2, 4 and $24 \mathrm{~h}$ after start of injection. Urine was collected during $24 \mathrm{~h}$ after injection. The chemical status of the radioactive compounds in blood and urine was analysed as a function of time using HPLC techniques.

Calcitonin levels were determined by the standard laboratory procedure in the hospital (radioimmunoassay, upper normal value $0.14 \mu \mathrm{g} / \mathrm{l}$ ) in blood samples taken shortly before and at 2, 5 and $10 \mathrm{~min}$ after start of administration of the radioligands.

\section{Results}

\section{Administration}

Administration of the radioligands was often followed by a clear increase of serum calcitonin levels (Fig. 1) and was sometimes associated with mild side effects; these were different in the various patients. Side effects during administration were increase of heart rate (maximum heart rate $105 \mathrm{bpm}$, rise only experienced by one patient), flushes (four patients), mild pressure on the chest (two patients), mild nausea (four patients, no vomiting), paraesthesia in the hands (two patients) and in one patient some dizziness. In one patient 


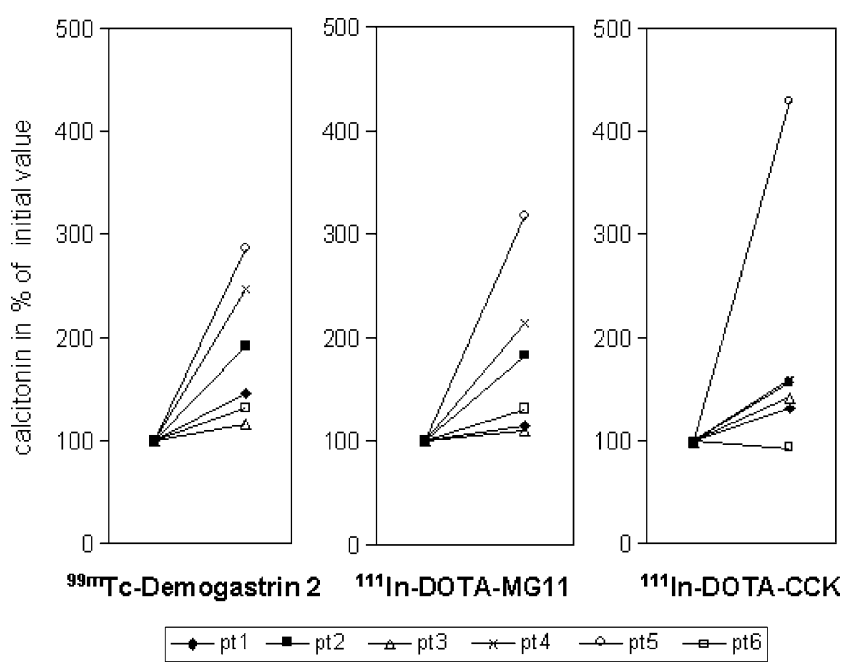

Fig. 1 Calcitonin levels (highest measured concentrations) after administration of the radioligands. Calcitonin levels in percentages of the initial calcitonin measurements (set at 100\%)

(patient 5) ${ }^{111}$ In-DOTA-CCK caused the most side effects; this was the only patient with calcitonin levels clearly higher after administration of ${ }^{111}$ In-DOTA-CCK compared to calcitonin levels after administration of the other radioligands (Fig. 1). In three (of six) patients, ${ }^{99 \mathrm{~m}} \mathrm{Tc}$-demogastrin 2 caused the most side effects and two patients did not have any side effects at all. All side effects were mild and disappeared spontaneously within 10 min after administration (heart rate normalised within $2 \mathrm{~min}$ ). Two patients previously had a pentagastrin stimulation test and both judged the side effects of that test to be far more severe.

\section{Biodistribution}

The dynamic series obtained during the first $30 \mathrm{~min}$ p.i. showed radioactivity in blood pool, kidneys and stomach in all patients. Visualisation of the (strong CCK-2 receptorpositive [12]) stomach was clearest with ${ }^{99 \mathrm{~m}} \mathrm{Tc}$-demogastrin 2. Total body images showed accumulation in joint regions (such as shoulders, hips, lumbar spine), nipples and in breasts of premenopausal women as well. In some patients tumour uptake was already visible in this early time frame. On the 3-4 h p.i. images, clear visualisation of the stomach was observed, especially with ${ }^{99 \mathrm{~m}} \mathrm{Tc}$-demogastrin 2 . Besides uptake in joint regions, breasts and nipples and the activity in the kidneys and bladder, there was also radioactivity in the bowel. ${ }^{111}$ In-DOTA-CCK showed some activity in the liver, ${ }^{111}$ In-DOTA-MG11 showed less liver activity and with ${ }^{99 \mathrm{~m}} \mathrm{Tc}$-demogastrin 2 the liver was hardly visible. At this time point more tumour lesions were recognised, best with ${ }^{99 \mathrm{~m}}$ Tc-demogastrin 2. Physiological activity in joint regions and breasts decreased over time, whereas activity in tumour lesions was more stable. This resulted in easier interpretation of the images at later time points, especially at $7 \mathrm{~h}$ p.i. (Fig. 2). At 24 h p.i. most tumour lesions were still visible, even with ${ }^{99 \mathrm{~m}} \mathrm{Tc}$-demogastrin 2 , partly due to the very low background activity.

\section{Lesion detection}

${ }^{99 \mathrm{~m}} \mathrm{Tc}$-demogastrin 2 visualised all known lesions. In addition this analogue visualised in four patients unknown lesions in the neck (two patients), brain (one patient), bone
Fig. 2 Scintigrams of patient 6 (anterior view): 1st row ${ }^{99 \mathrm{~m}} \mathrm{Tc}-$ demogastrin 2, 2nd row ${ }^{111} \mathrm{In}$ DOTA-MG11 and 3rd row ${ }^{111}$ In-DOTA-CCK at 4, 7 and 24 h p.i., respectively. Decreasing activity in sternoclavicular (SC) joints over time simplifying interpretation (especially for ${ }^{111}$ In-DOTA compounds). Best tumour visualisation with ${ }^{99 \mathrm{~m}} \mathrm{Tc}$ demogastrin 2 at $7 \mathrm{~h}$ p.i. Tumour lesions in neck marked with closed arrows, left SC joint with open arrows

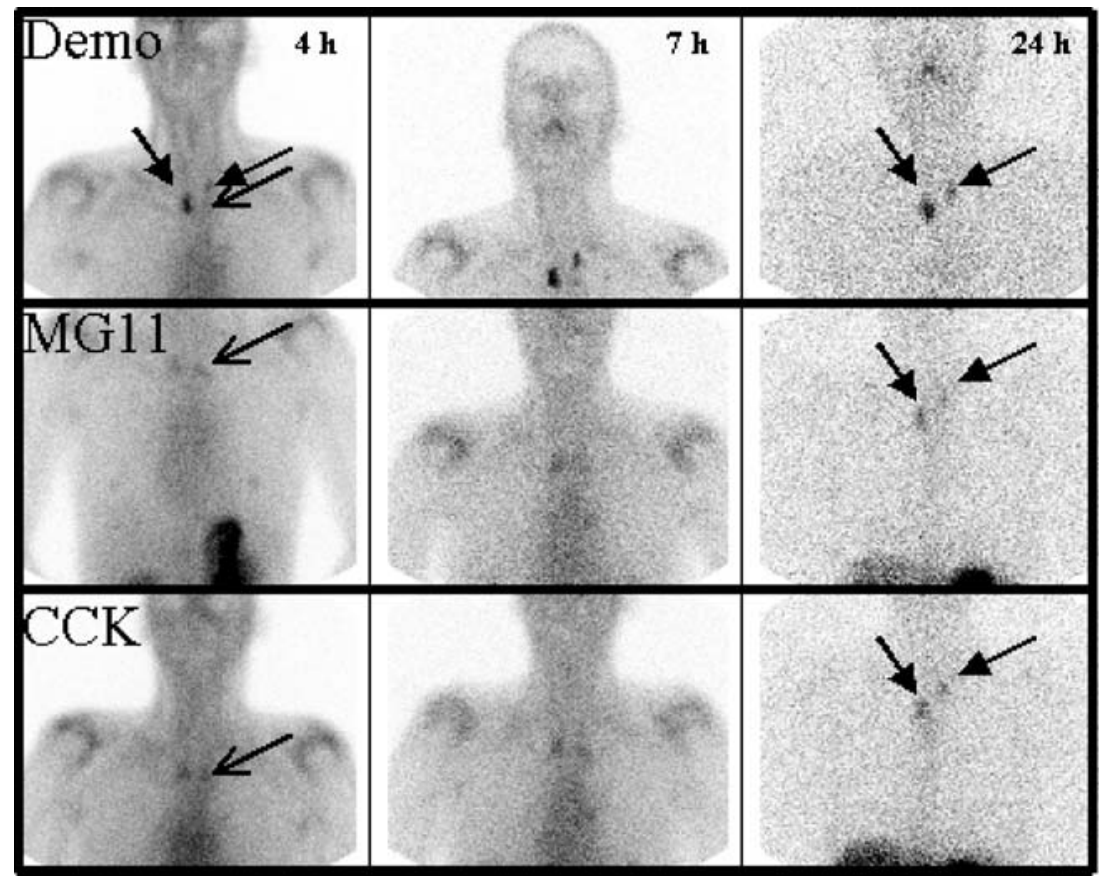


(one patient) and/or liver (one patient). With the other two compounds several known lesions were missed and fewer new lesions were discovered. New liver lesions in one patient were not visible with ${ }^{111}$ In-DOTA-CCK; neck lesions in another patient could only be recognised on the ${ }^{99 \mathrm{~m}} \mathrm{Tc}$-demogastrin 2 scan. An unknown lesion in the brain was only retrospectively seen with the two ${ }^{111}$ In-DOTA compounds (after localisation with ${ }^{99 \mathrm{~m}} \mathrm{Tc}$-demogastrin 2 ). In each of the four patients with new lesions at least one of the new lesions was confirmed by additional imaging with US, CT or MRI. A neck lesion only visible on ${ }^{99 \mathrm{~m}} \mathrm{Tc}$ demogastrin 2 scintigraphy was confirmed by US-guided fine-needle aspiration cytology as a 6-mm true positive lesion (patient 4). In patient 2 cytologic investigation of the brain lesion was not possible because of the location of the lesion. MRI images could not differentiate between tumour or pineal cyst. Results are listed in Table 1. Figures 3 and 4 show examples of the comparative images of the three radiopharmaceuticals in two of the six patients studied.

\section{Renal uptake}

Visually there were no clear differences in renal uptake between the three compounds; the stomach (CCK-2 receptor-positive) to kidney ratio seemed best with ${ }^{99 \mathrm{~m}} \mathrm{Tc}$ demogastrin 2 (Fig. 5). Renal uptake calculation was hampered by overprojection of activity in stomach and bowel. To recognise important differences in renal uptake, regions without overprojection of other activity-accumulating organs were chosen. In three patients these regions were available for all three radioligands (and time points), and in these patients renal uptake values were in the same range (uptake in left kidney: for ${ }^{111}$ In-DOTA-CCK, ${ }^{111}$ In-DOTA-MG11 and ${ }^{99 \mathrm{~m}} \mathrm{Tc}$-demogastrin 2 , respectively, $0.62 \pm 0.27,0.37 \pm 0.19$ and $0.48 \pm 0.22 \% \mathrm{ID}$ at $\pm 4 \mathrm{~h}$ p.i. and $0.25 \pm 0.10,0.16 \pm 0.04$ and $0.27 \pm 0.07 \% \mathrm{ID}$ at $\pm 24 \mathrm{~h}$ p.i.).

\section{Radioactivity in blood and urine}

Serum radioactivity and urine radioactivity of all three radioligands were analysed in five patients; detailed results are described elsewhere [11]. Briefly, there were neither statistically significant differences in the decrease of serum radioactivity nor in the (very fast) urinary excretion of radioactivity for the three compounds. HPLC blood analyses, however, showed clear differences in the degradation rates of the analogues. In blood samples taken at $10 \mathrm{~min}$ after start of administration $64 \pm 6 \%$ of ${ }^{99 \mathrm{~m}} \mathrm{Tc}$-demogastrin 2 was still intact. At the same early time point only $38 \pm 9 \%$ of ${ }^{111} \mathrm{In}$ DOTA-CCK and $9 \pm 3 \%$ of ${ }^{111}$ In-DOTA-MG11 was still intact.

\section{Discussion}

Patients with residual or recurrent MTC after surgery can be potentially cured if lesions are limited to the neck region. Inasmuch as available diagnostic modalities often fail to

Table 1 Lesions visualised using the three radiopharmaceuticals

\begin{tabular}{|c|c|c|c|}
\hline & ${ }^{99 \mathrm{~m}} \mathrm{Tc}$-demogastrin 2 & ${ }^{111}$ In-DOTA-MG11 & ${ }^{111}$ In-DOTA-CCK \\
\hline Patient 1 & Neck & None & Neck equivocal \\
\hline Calcitonin $15 \mu \mathrm{g} / 1$ & Liver & & \\
\hline Patient $2^{\mathrm{a}}$ & Neck/mediastinum & Neck/mediastinum & Neck/mediastinum \\
\hline Calcitonin $49 \mu \mathrm{g} / 1$ & Brain (unknown, $\mathrm{MRI}+^{\mathrm{a}}$ ) & Brain equivocal (retrospective) & Brain (retrospective) \\
\hline $\begin{array}{l}\text { Patient } 3^{\mathrm{b}} \\
\text { Calcitonin } 0.33 \mu \mathrm{g} / 1\end{array}$ & Neck (4 lesions, 2 unknown $^{\mathrm{b}}$ ) & Neck (4 lesions, 2 unknown ${ }^{\text {b }}$ ) & Neck (2 lesions) \\
\hline $\begin{array}{l}\text { Patient } 4 \\
\text { Calcitonin } 0.23 \mu \mathrm{g} / 1\end{array}$ & $\begin{array}{l}\text { Neck (2 lesions, } 1 \text { unknown) } \\
\text { Unknown lesion: FNA: MTC+ }\end{array}$ & None & None \\
\hline Patient $5^{\mathrm{c}}$ & Neck & Neck & Neck \\
\hline \multirow[t]{2}{*}{ Calcitonin $35 \mu \mathrm{g} / 1$} & $\begin{array}{l}\text { Mediastinum } \\
\text { Liver (unknown, MRI+) }\end{array}$ & $\begin{array}{l}\text { Mediastinum } \\
\text { Liver (unknown, MRI+) }\end{array}$ & Mediastinum \\
\hline & Bone (unknown, $\mathrm{CT}+$ ) & Bone (unknown, CT+) & Bone (unknown, $\mathrm{CT}+$ ) \\
\hline Patient $6^{\mathrm{c}}$ & Neck & Neck & Neck \\
\hline \multirow[t]{3}{*}{ Calcitonin $131 \mu \mathrm{g} / 1$} & Lungs & Lungs & Lungs \\
\hline & Liver & Liver & Liver \\
\hline & Bone & Bone & Bone \\
\hline
\end{tabular}

${ }^{a}$ MRI: pineal cyst possible. Lesion with ${ }^{111}$ In-DOTA-MG11 and ${ }^{111}$ In-DOTA-CCK missed on initial reading

${ }^{\mathrm{b}}$ Not all lesions could be confirmed by US

${ }^{\mathrm{c}}$ Lesions in patients 5 and 6 best visible with ${ }^{99 \mathrm{~m}}$ Tc-demogastrin 2 (Figs. 2 and 4) 
Fig. 3 Scintigrams of patient 1 (anterior and posterior views): 1st row ${ }^{99 \mathrm{~m}} \mathrm{Tc}$-demogastrin 2 at $4 \mathrm{~h}$ and $24 \mathrm{~h}, 2$ nd row ${ }^{111}$ InDOTA-MG11 at $4 \mathrm{~h}$ and $24 \mathrm{~h}$ and 3 rd row ${ }^{111}$ In-DOTA-CCK at $4 \mathrm{~h}$ and $24 \mathrm{~h}$. Tumour lesions (and stomach) are best visible on ${ }^{99 \mathrm{~m}} \mathrm{Tc}$-demogastrin 2 scintigraphy; some lesions are marked with arrows

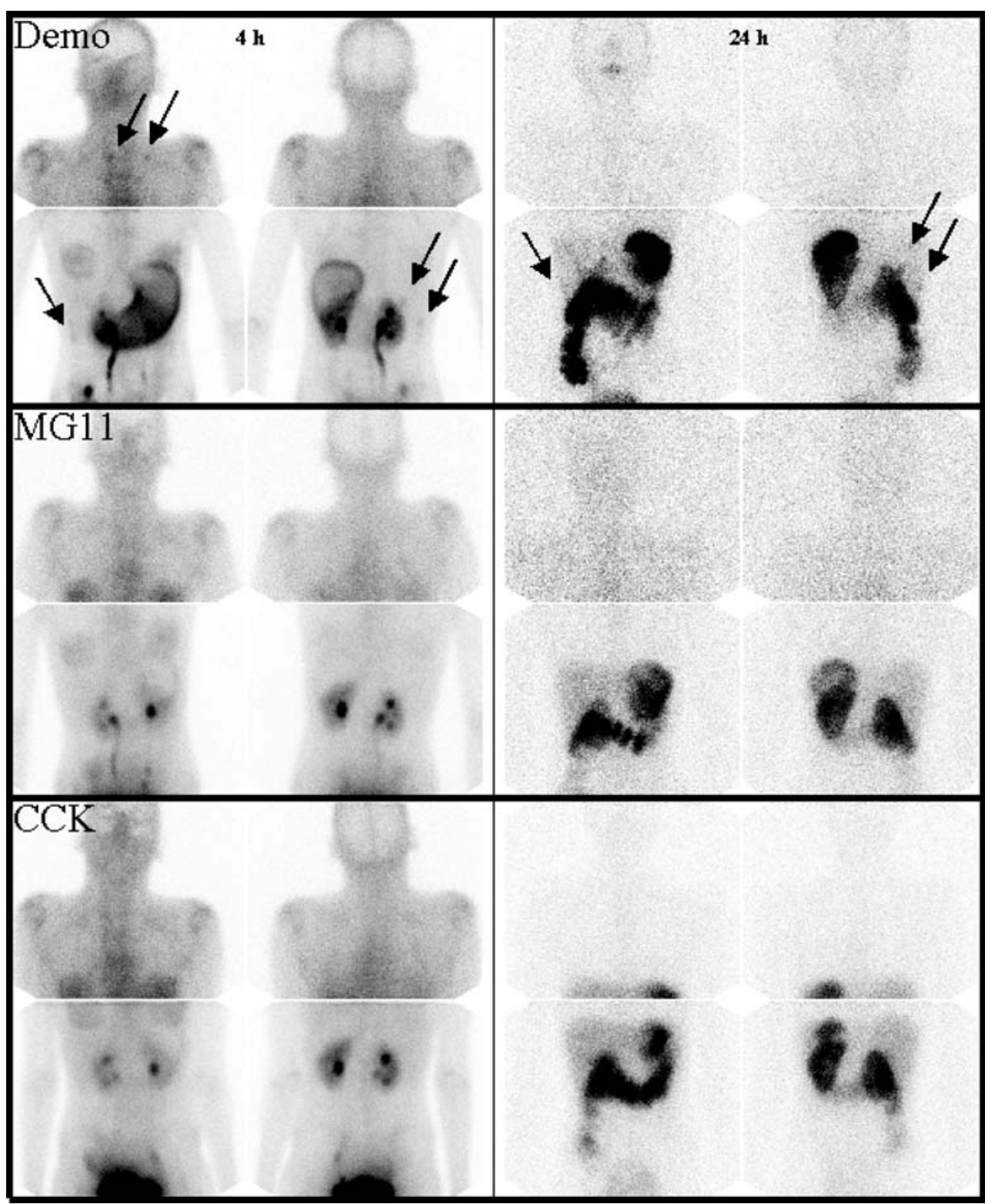

detect the tumour lesions in patients with slightly elevated serum calcitonin levels, a more sensitive modality is needed. Furthermore, there is a strong impetus for the development of PRRT, based on targeting CCK-2 receptors, because there is currently no effective therapy available for patients with distant metastases of MTC.

Comparison of the results of several studied CCK-2 receptor-binding compounds [4-8] used in various and sometimes small patient groups is of limited value. Nevertheless, the promising results of a number of preclinical, as well as a few clinical studies using radiolabelled CCK-2 receptor-binding peptides, have shown that these compounds might be useful in the management of patients with MTC (and possibly other CCK-2 receptorpositive tumours $[1,13])$. We therefore carried out a more controlled study that allows for the direct comparison of promising CCK-2 receptor-targeted analogues in the same patients in an attempt to find the best analogue for tumour localisation and test the potential of the two ${ }^{111}$ In-DOTA compounds for PRRT.

Comparing the results of the analogues tested, ${ }^{99 \mathrm{~m}} \mathrm{Tc}$ demogastrin 2 scintigraphy showed the most promising results. All known tumour lesions were visualised and in four of six patients new lesions were discovered. Even in two patients with rather low calcitonin levels (patients 3 and 4) lesions were visible. Both ${ }^{111}$ In-DOTA-MG11 and ${ }^{111}$ InDOTA-CCK were less suitable for scintigraphy as image quality was inferior and several lesions were missed that were observed with ${ }^{99 \mathrm{~m}} \mathrm{Tc}$-demogastrin 2 . The scintigraphic results of the ${ }^{111}$ In-labelled peptides were disappointing as not only the sensitivity but also the uptake in the visible lesions was limited and appeared to be insufficient for 


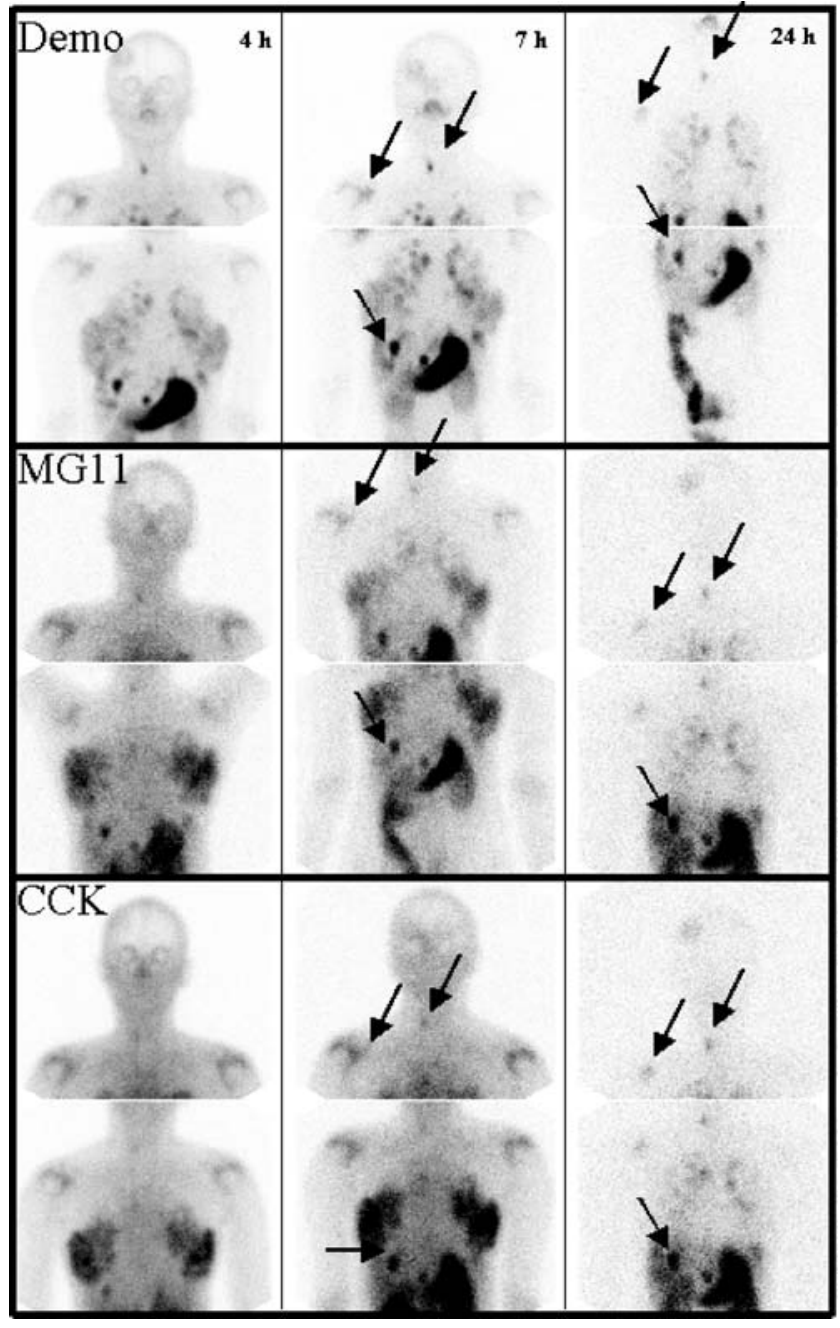

Fig. 4 Scintigrams of patient 5 (anterior view, young woman with known mastopathy): 1st row ${ }^{99 \mathrm{~m}} \mathrm{Tc}-$ demogastrin 2 , 2nd row ${ }^{111} \mathrm{In}$ DOTA-MG11 and $3 r d$ row ${ }^{111}$ In-DOTA-CCK at 4, 7 and $24 \mathrm{~h}$ p.i., respectively (activity in breast tissue decreasing over time). Clearest visualisation of known tumour lesions in neck, lungs, liver and bone with ${ }^{99 \mathrm{~m}} \mathrm{Tc}$-demogastrin 2 (some lesions marked with arrows)

radionuclide therapy in these tumours, especially considering that MTC is reported to be radioresistant [14].

The variation in diagnostic performance among the three tracers is probably the combined result of several parameters. It is well known that ${ }^{99 \mathrm{~m}} \mathrm{Tc}$ has better imaging properties than ${ }^{111}$ In. Furthermore, a higher specific activity labelling could be achieved with ${ }^{99 \mathrm{~m}} \mathrm{Tc}$-demogastrin 2 resulting in a higher injected activity (labelled to $10 \mu \mathrm{g}$ of the peptide). Another important parameter probably is the difference in the in vivo stability of the three radioligands. The stability of ${ }^{111} \mathrm{In}$ DOTA-MG11 was unexpectedly low. This peptide was previously reported to be stable in ex vivo human serum [9], but HPLC results of blood samples taken at 10 min after start of the administration showed that only approximately $10 \%$ of the original peptide was still intact. In contrast, ${ }^{99 \mathrm{~m}}$ Tc-demogastrin 2 was more stable; HPLC showed that on average more than $60 \%$ of the radioligand was intact at the same time point. Recently Good et al. reported a decreased mean lifetime and lower tumour uptake of ${ }^{111}$ In-DOTAMG11 in comparison with ${ }^{111}$ In-DTPA-DGlu ${ }^{1}$-minigastrin [15]. Therefore, the diagnostic efficacy of ${ }^{111}$ In-DOTA-MG11 might be inferior to that of ${ }^{111}$ In-DTPA-DGlu ${ }^{1}$-minigastrin [5, 6]. Gotthardt et al. reported a tumour detection rate of $87 \%$ by scintigraphy using this compound in a group of 26 MTC patients. Most of the patients included in that study, however, had known metastases and in the group of patients with occult disease $(n=5)$ tumour lesions were found in only one patient. A direct comparison between ${ }^{111}$ In-DTPA-DGlu ${ }^{1}$ minigastrin and ${ }^{99 \mathrm{~m}} \mathrm{Tc}$-demogastrin 2 would be of interest.

The renal uptake of the three test compounds was also of interest, considering the previous report by Béhé and Behr [5], who observed that therapy with ${ }^{90} \mathrm{Y}_{\text {-DTPA-DGlu }}{ }^{1}$ minigastrin caused renal damage. Calculation of renal uptake values was impaired by overprojection of activity in bowel and stomach that changed over time. However, visual evaluation and an estimation of renal uptake made clear that the differences in renal uptake were far less than expected. In particular, the renal uptake of ${ }^{99 \mathrm{~m}} \mathrm{Tc}$-demogastrin 2 was in the same range as the uptake of ${ }^{111}$ In-DOTA-MG11 and ${ }^{111}$ In-DOTA-CCK, although in previous animal studies kidney radioactivity levels were high in comparison with ${ }^{111}$ In-DOTA-MG11 and ${ }^{111}$ In-DOTA-CCK [7, 9, 16].

Béhé et al. [17] reported high uptake of ${ }^{111}$ In-DTPA${ }_{\text {DGlu }}{ }^{1}$-minigastrin in the kidneys of mice. This renal uptake could be significantly blocked by coinjection of polygluta-

Fig. 5 Scintigrams of patient 1 (untruncated posterior views, $24 \mathrm{~h}$ p.i.) to judge kidney uptake (open arrows) in relation to stomach uptake (closed arrows). $1 s t{ }^{99 \mathrm{~m}} \mathrm{Tc}$-demogastrin 2, 2nd

${ }^{111}$ In-DOTA-MG11 and $3 r d$

${ }^{111}$ In-DOTA-CCK

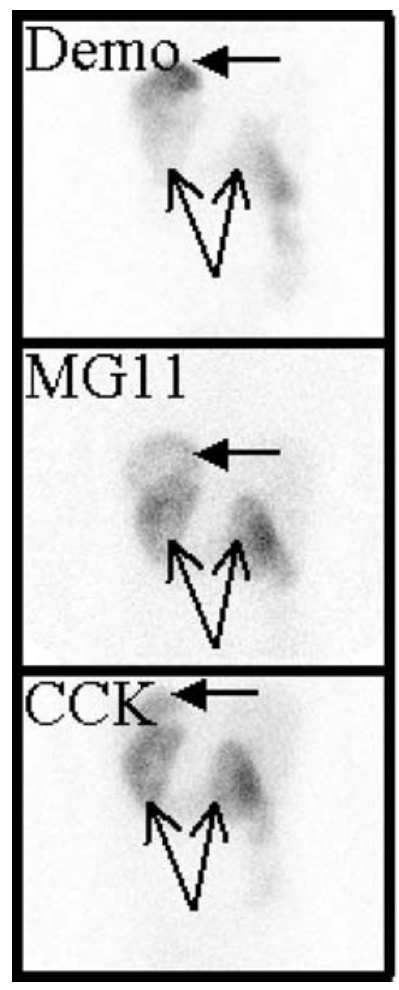


mic acids, whereas tumour uptake was not impaired, resulting in a higher tumour to kidney ratio. If polyglutamic acid coinjection is well tolerated by patients, this method might be useful to reduce nephrotoxicity after PRRT with ${ }^{90}$ Y-DTPA-DGlu ${ }^{1}$-minigastrin or other gastrin-like analogues. The commonly used plasma expander Gelofusin ${ }^{\circledR}$ might also be useful for lowering renal uptake. Gotthardt et al. reported a significant reduction of renal accumulation (45\%) of ${ }^{111} \mathrm{In}-$ DTPA-DGlu ${ }^{1}$-minigastrin in rats using Gelofusin ${ }^{\circledR}$ [18]. Potential bone marrow toxicity of ${ }^{90}$ Y-DTPA-DGlu $^{1}$-minigastrin might remain a cause of concern, because the reported activity in blood and other organs was not lower after use of polyglutamic acids [16]. These various findings imply that further improvement can be made to enhance the efficacy of CCK-2 receptor-binding ligands for PRRT. As ${ }^{99 \mathrm{~m}} \mathrm{Tc}-$ demogastrin 2 showed most tumour lesions and renal uptake of this analogue was lower than expected, ${ }^{188}$ Re-demogastrin 2 might be one of the potential radiopharmaceuticals which deserves further investigation.

From our results we conclude that: (1) ${ }^{99 \mathrm{~m}} \mathrm{Tc}$-demogastrin 2 scintigraphy appears to be a very promising diagnostic tool in patients with evidence of recurrence or metastases of MTC. Further studies are warranted to investigate its value in patient management. (2) In this small group of patients tumour uptake of either ${ }^{111}$ In-DOTA-MG11 or ${ }^{111}$ In-DOTACCK was less promising for imaging and was considered too low to expect any beneficial effect from PRRT. To enable therapy with CCK-2 receptor-binding radiolabelled analogues further research is needed and should be aimed towards designing stable compounds which retain high receptor affinity but in addition have more favourable biodistribution profiles including low renal retention.

Acknowledgments The authors want to thank Professor Dr. Mäcke for the gift of DOTA-MG11 (designed as part of a joint project within the EU COST B12 action) and all the members of EU COST Actions B12 and BM0607 for collaborations and stimulating discussions. They also thank Erik de Blois, Arthur van Gameren, Caroline Lansbergen-Hijmans and all other nuclear medicine technicians involved for their support in preparation of the radioligands and the laboratory and scintigraphic investigations.

Open Access This article is distributed under the terms of the Creative Commons Attribution Noncommercial License which permits any noncommercial use, distribution, and reproduction in any medium, provided the original author(s) and source are credited.

\section{References}

1. Reubi JC, Waser B. Unexpected high incidence of cholecystokinin$\mathrm{B} /$ gastrin receptors in human medullary thyroid carcinomas. Int $\mathrm{J}$ Cancer 1996;67:644-7. doi:10.1002/(SICI)1097-0215(19960904) 67:5<644::AID-IJC9>3.0.CO;2-U.

2. Krenning EP, Kwekkeboom DJ, Bakker WH, Breeman WA, Kooij PP, Oei HY, et al. Somatostatin receptor scintigraphy with (111In-DTPA-D-Phe1)-and (123I-Tyr3-octreotide: the Rotter- dam experience with more than 1000 patients. Eur J Nucl Med 1993;20:716-31. doi:10.1007/BF00181765.

3. Kwekkeboom DJ, Mueller-Brand J, Paganelli G, Anthony LB, Pauwels S, Kvols LK, et al. Overview of results of peptide receptor radionuclide therapy with 3 radiolabeled somatostatin analogs. J Nucl Med 2005;46 Suppl 1:62S-6S.

4. Behr TM, Jenner N, Béhé M, Angerstein C, Gratz S, Raue F, et al. Radiolabelled peptides for targeting of cholecystokinin-B/gastrin receptor expressing tumours: from preclinical development to initial clinical results. J Nucl Med 1999;40:1029-44.

5. Béhé M, Behr TM. Cholecystokinin-B (CCK-B)/gastrin receptor targeting peptides for staging and therapy of medullary thyroid cancer and other CCK-B receptor expressing malignancies. Biopolymers 2002;66:399-418. doi:10.1002/bip.10356.

6. Gotthardt M, Béhé MP, Beuter D, Battmann A, Bauhofer A, Schurrat $\mathrm{T}$, et al. Improved tumour detection by gastrin receptor scintigraphy in patients with metastasised medullary thyroid carcinoma. Eur J Nucl Med Mol Imaging 2006;33:1273-9. doi:10.1007/s00259-006-0157-8.

7. Nock BA, Maina T, Béhé M, Nikolopoulou A, Gotthardt M, Schmitt JS, et al. CCK-2/gastrin receptor-targeted tumor imaging with $(99 \mathrm{~m})$ Tc-labeled minigastrin anologs. J Nucl Med 2005;46:1727-36.

8. Kwekkeboom DJ, Bakker WH, Kooij PPM, Erion J, Srinivasan A, De Jong $\mathrm{M}$, et al. Cholecystokinin receptor imaging using an octapeptide DTPA-CCK analogue in patients with medullary thyroid carcinoma. Eur J Nucl Med 2000;27:1312-7. doi:10.1007/ s002590000296.

9. Béhé M, Reubi J, Nock B, Mäcke H, Breeman WAP, Bernard HF, et al. Evaluation of a DOTA-minigastrin derivative for therapy and diagnosis for CCK-2 receptor positive tumours. Eur J Nucl Med Mol Imaging 2005;32 Suppl 1:S78.

10. Breeman WAP, De Jong M, Visser TJ, Erion JL, Krenning EP. Optimising conditions for radiolabelling of DOTA-peptides with 90Y, $111 \mathrm{In}$ and $177 \mathrm{Lu}$ at high specific activities. Eur J Nucl Med Mol Imaging 2003;30:917-20.

11. Breeman WAP, Fröberg AC, de Blois E, van Gameren A, Melis M, de Jong $\mathrm{M}$, et al. Optimised labeling, preclinical and initial clinical aspects of CCK-2 receptor-targeting with 3 radiolabeled peptides. Nucl Med Biol 2008;35:839-49. doi:10.1016/j.nucmedbio.2008.09.006.

12. Reubi JC, Waser B, Läderach U, Stettler C, Friess H, Halter F, et al. Localization of cholecystokinin A and cholecystokinin Bgastrin receptors in the human stomach. Gastroenterology 1997;112:1197-205. doi:10.1016/S0016-5085(97)70131-8.

13. Gotthardt M, Béhé MP, Grass J, Bauhofer A, Rinke A, Schipper M, et al. Added value of gastrin receptor scintigraphy in comparison to somatostatin receptor scintigraphy in patients with carcinoids and other neuroendocrine tumours. Endocr Relat Cancer 2006;13:120311. doi:10.1677/erc.1.01245.

14. Cox JD. Moss' radiation oncology: rationale, technique, results. St. Louis: Mosby; 1994. p. 290-295.

15. Good S, Walter MA, Waser B, Wang X, Müller-Brand J, Béhé MP, et al. Macrocyclic chelator-coupled gastrin-based radiopharmaceuticals for targeting of gastrin receptor-expressing tumours. Eur J Nucl Med Mol Imaging 2008;35:1868-77. doi:10.1007/s00259-008-0803-4.

16. de Jong M, Bakker WH, Bernard BF, Valkema R, Kwekkeboom DJ, Reubi JC, et al. Preclinical and initial clinical evaluation of 111In-labeled nonsulfated CCK8 analog: a peptide for CCK-B receptor-targeted scintigraphy and radionuclide therapy. $\mathrm{J}$ Nucl Med 1999;40:2081-7.

17. Béhé M, Kluge G, Becker W, Gotthardt M, Behr TM. Use of polyglutamic acids to reduce uptake of radiometal-labeled minigastrin in the kidneys. J Nucl Med 2005;46:1012-5.

18. Gotthardt M, van Eerd-Vismale J, Oyen WJG, de Jong M, Zhang H, Rolleman E, et al. Indication for different mechanisms of kidney uptake of radiolabeled peptides. J Nucl Med 2007;48:596-601. doi:10.2967/jnumed.106.036020. 